\title{
Regional diastolic dysfunction in postischaemic myocardium in calf: effect of nisoldipine
}

Krogmann, O N ; Tjon-A-Meeuw, L ; Hess, O M ; Jacob, M ; Grimm, J ; Leskosek, B ; Pasic, M ; von Segesser, Ludwig K

\begin{abstract}
Objective: The aim was to assess the effect of nisoldipine on left ventricular systolic and diastolic function during prolonged myocardial ischaemia. Methods: The left circumflex coronary artery was ligated for $2 \mathrm{~h}$ and reperfused for $4 \mathrm{~h}$ in 12 calves. The animals were randomised to a control group $(n=6)$ or to treatment with $1.25 \mathrm{mg} \cdot \mathrm{h}-1$ intravenous nisoldipine $(\mathrm{n}=6)$ during $2 \mathrm{~h}$ of ischaemia. Circulatory support by a ventricular assist device was performed throughout the experiment except for the time of haemodynamic measurements. Regional wall thickening of a normal and an ischaemic left ventricular region was determined using pairs of ultrasonic crystals. Left ventricular pressure was measured by micromanometry. Left ventricular wall thickness and regional wall stiffness at a common preload of $10 \mathrm{~mm} \mathrm{Hg}$ were calculated using an elastic model with shifting asymptote. Results: Ten animals survived after $6 \mathrm{~h}$. No difference was observed in systolic function between controls and nisoldipine treated animals. Systolic thickening of the ischaemic wall remained depressed $4 \mathrm{~h}$ after reperfusion and showed some recovery after dopamine infusion. Ischaemic wall stiffness at a common preload was lower after nisoldipine during ischaemia and reperfusion than in controls. Control wall stiffness remained unchanged during the whole experiment with and without nisoldipine. Diastolic thinning of the ischaemic wall was prevented by nisoldipine during ischaemia and after reperfusion. Conclusions: Prolonged myocardial ischaemia is associated with increased myocardial stiffness of the ischaemic wall. Mechanical unloading can help to bridge the acute phase but cannot prevent postischaemic diastolic dysfunction of the ischaemic wall. Nisoldipine has a beneficial effect on regional diastolic function during ischaemia and reperfusion by decreasing regional wall stiffness and preventing diastolic thinning of the ischaemic wall. Cardiovascular Research 1993;27:531-536
\end{abstract}

DOI: https://doi.org/10.1093/cvr/27.3.531

Posted at the Zurich Open Repository and Archive, University of Zurich

ZORA URL: https://doi.org/10.5167/uzh-154809

Journal Article

Published Version

Originally published at:

Krogmann, O N; Tjon-A-Meeuw, L; Hess, O M; Jacob, M; Grimm, J; Leskosek, B; Pasic, M; von Segesser, Ludwig K (1993). Regional diastolic dysfunction in postischaemic myocardium in calf: effect of nisoldipine. Cardiovascular Research, 27(3):531-536.

DOI: https://doi.org/10.1093/cvr/27.3.531 


\title{
Regional diastolic dysfunction in postischaemic myocardium in calf: effect of nisoldipine
}

\author{
O N Krogmann, L Tjon-A-Meeuw, O M Hess, M Jacob, J Grimm, B Leskosek, \\ $M$ Pasic, and L v Segesser
}

\begin{abstract}
Objective: The aim was to assess the effect of nisoldipine on left ventricular systolic and diastolic function during prolonged myocardial ischaemia. Methods: The left circumflex coronary artery was ligated for $2 \mathrm{~h}$ and reperfused for $4 \mathrm{~h}$ in 12 calves. The animals were randomised to a control group $(n=6)$ or to treatment with $1.25 \mathrm{mg} \cdot \mathrm{h}^{-1}$ intravenous nisoldipine $(\mathrm{n}=6)$ during $2 \mathrm{~h}$ of ischaemia. Circulatory support by a ventricular assist device was performed throughout the experiment except for the time of haemodynamic measurements. Regional wall thickening of a normal and an ischaemic left ventricular region was determined using pairs of ultrasonic crystals. Left ventricular pressure was measured by micromanometry. Left ventricular wall thickness and regional wall stiffness at a common preload of $10 \mathrm{~mm} \mathrm{Hg}$ were calculated using an elastic model with shifting asymptote. Results: Ten animals survived after $6 \mathrm{~h}$. No difference was observed in systolic function between controls and nisoldipine treated animals. Systolic thickening of the ischaemic wall remained depressed $4 \mathrm{~h}$ after reperfusion and showed some recovery after dopamine infusion. Ischaemic wall stiffness at a common preload was lower after nisoldipine during ischaemia and reperfusion than in controls. Control wall stiffness remained unchanged during the whole experiment with and without nisoldipine. Diastolic thinning of the ischaemic wall was prevented by nisoldipine during ischaemia and after reperfusion. Conclusions: Prolonged myocardial ischaemia is associated with increased myocardial stiffness of the ischaemic wall. Mechanical unloading can help to bridge the acute phase but cannot prevent postischaemic diastolic dysfunction of the ischaemic wall. Nisoldipine has a beneficial effect on regional diastolic function during ischaemia and reperfusion by decreasing regional wall stiffness and preventing diastolic thinning of the ischaemic wall.
\end{abstract}

Cardiovascular Research 1993;27:531-536

$\mathrm{P}$ rolonged myocardial ischaemia is associated with regional myocardial dysfunction which can persist for hours and days and may lead to irreversible myocardial damage. Diastolic dysfunction has been reported in the experimental animal during acute ischaemia ${ }^{1-3}$ as well as during postreperfusion myocardial stunning. ${ }^{+5}$ Administration of calcium antagonists beneficially influences diastolic dysfunction after short term ischaemia. ${ }^{6}$ However, long term ischaemia has not yet been studied with regard to diastolic dysfunction and its reversibility with calcium antagonists. Long term ischaemia is often associated with variable myocardial damage and may be accompanied by severe arrhythmias and low output failure. ${ }^{7-9}$ It has been shown previously that systolic function can be preserved during long term myocardial ischaemia by extracorporeal circulatory support. ${ }^{10-12}$ However, the effect of prolonged ischaemia on regional diastolic dysfunction was not evaluated. Thus the purpose of the present study was (1) to assess the effect of long term myocardial ischaemia on regional diastolic dysfunction and (2) to determine the influence of nisoldipine, a new calcium antagonist of the dihydropyridine group, on regional passive elastic properties of the ischaemic and postischaemic myocardium.

\section{Methods}

Twelve calves with a mean body weight of $72 \mathrm{~kg}$ underwent left thoracotomy under general anaesthesia with $0.25 \mathrm{mg} \cdot \mathrm{kg}^{-1}$ Polamivet (morphine derivative) and $0.04 \mathrm{mg} \cdot \mathrm{kg}^{-1}$ Combelen (phenothiazine derivative) in combination with $10 \mathrm{mg} \cdot \mathrm{kg}^{-1}$ thiopentone. Animals were treated in accordance with the principles of laboratory animal care at our hospital. The study protocol was approved by the local animal ethics committee. The preparation of the animals and the instrumentation used in this study have been described in detail elsewhere. ${ }^{12}$ Briefly, the left atrium and the descending aorta as well as the right atrium and the pulmonary artery were cannulated surgically and connected to a ventricular assist device (Abiomed model 5000 Danvers, MA. USA). This device includes a driving unit and a disposable paracorporeal blood system which is connected to the right atrium and the pulmonary artery or to the left atrium and the aorta. The assist device contains two chambers and two trileaflet valves for flow direction ${ }^{13-15}$ Left ventricular pressure was measured with an $8 \mathrm{~F}$ Millar pigtail micromanometer catheter which was inserted through the left atrial appendage into the left ventricle. Aortic pressure was determined with a fluid filled $8 \mathrm{~F}$ pigtail catheter which was positioned in the ascending aorta. Pairs of ultrasonic crystals were implanted in the region perfused by the left anterior descending coronary artery (=control wall) and in the region perfused by the left circumflex coronary artery (=ischaemic wall) for measuring left ventricular wall thickness. ${ }^{3 / \mathrm{ln}}$ Coronary blood flow velocity in the proximal left anterior descending and the left circumflex coronary arteries was measured by Doppler sonomicrometry (Triton Technology, San Diego, CA, USA) using two Doppler flow probes with an internal diameter of $3 \mathrm{~mm}$ Myocardial ischaemia was induced by ligation of the left circumflex coronary artery. The Doppler probe was placed approximately $2 \mathrm{~cm}$ distal to the ligature.

Experimental protocol (fig I)

After completion of the instrumentation, an interval of 10 to 15 min was allowed for stabilisation of the haemodynamic variables. Then the control run was performed, after which the circumflex artery was ligated for a total duration of $2 \mathrm{~h}$. During the $2 \mathrm{~h}$ of ischaemia a continuous infusion of intravenous nisoldipine $\left(1.25 \mathrm{mg} \cdot \mathrm{h}^{-1}\right)$ was given in six randomly selected animals (nisoldipine group), whereas the other six animals served as controls (control group). Two hours after ligation of the left circumflex coronary artery, the vessel was released. nisoldipine infusion stopped, and the heart reperfused for the following

Division of Cardiology, Department of Internal Medicine, University Hospital, Raemistrasse 100, 8091 Zurich, Switzerland: O N Krogmann, L Tjon-A-Meeuw, O M Hess, M Jakob, J Grimm; Department of Cardiovascular Surgery: B Leskosek, M Pasic, L v Segesser. Correspondence to Dr Hess. 


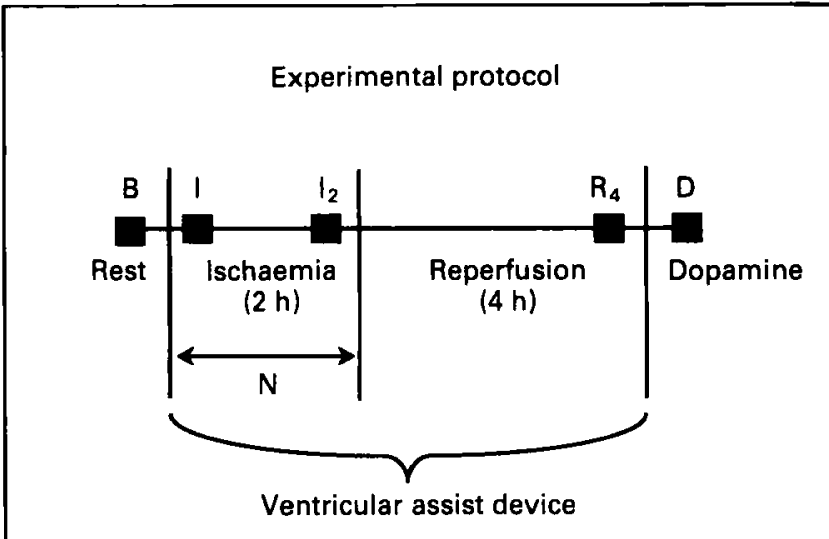

Haemodynamic measurements; $\mathbf{N}=$ nisoldipine infusion

Figure 1 Experimental protocol: haemodynamic measurements were performed at rest $(B)$, after $2 \min (I)$ and $2 h\left(I_{2}\right)$ of ischaemia, after $4 \mathrm{~h}$ of reperfusion $\left(R_{4}\right)$, and during dopamine infusion $(D)$ $\left(1000 \mu \mathrm{g} \cdot \mathrm{min}^{-1}\right)$. Ventricular unloading was started immediately after the induction of ischaemia and was continued throughout the experiment. Nisoldipine $(N)$ was given intravenously during the $2 \mathrm{~h}$ of ischaemia.

$4 \mathrm{~h}$. Unloading of both ventricles was performed from the beginning of ischaemia to the end of the experiment (fig 1). This procedure was necessary because ventricular fibrillation occurred frequently due to the extent and duration of the ischaemia. Thus there was no control group without unloading. Haemodynamic measurements were carried out at rest, after $2 \mathrm{~min}, 1 \mathrm{~h}$, and $2 \mathrm{~h}$ of ischaemia as well as after 1,2 , and $4 \mathrm{~h}$ of reperfusion (fig 2). During the short time period in which the measurements were performed, the assist device was stopped. After turning off the device the heart was allowed to regain its normal pump function with stable blood pressure for 1 to 3 min [mean 113 (SD 88) s]. At the end of the experiment the assist device was turned off and the haemodynamic measurements were repeated at rest and under inotropic stimulation with dopamine, starting at a dose of $250 \mu \mathrm{g} \cdot \mathrm{min}^{-1}$ and increasing at $2 \mathrm{~min}$ intervals to 500 and $1000 \mu \mathrm{g} \cdot \mathrm{min}^{-1}$. Data are reported at rest, after $2 \mathrm{~min}$ and $2 \mathrm{~h}$ of ischaemia, after $4 \mathrm{~h}$ of reperfusion, and during dopamine infusion with $100 \mu \mathrm{g} \cdot \mathrm{min}^{-1}$ (fig 2).

\section{Data analysis}

Left ventricular pressure and wall thickness tracings were digitised manually for three cardiac cycles using an electronic digitiser interfaced to a computer. Data were transferred to a personal computer for further analysis. Data were analysed for three cardiac cycles and plotted at 5 ms intervals.

Systolic function was assessed from systolic left ventricular wall thickening of the normal and ischaemic wall. Systolic wall thickening was calculated as end systolic minus end diastolic wall thickness divided by end diastolic wall thickness multiplied by 100 . End diastole was defined as the time of the rapid upstroke of $\mathrm{dP} / \mathrm{dt}$ and end systole as the time at which left ventricular pressure fell below aortic incisural pressure. Normalisation of left ventricular wall thickness was carried out according to Osakada and coworkers ${ }^{17}$ by dividing wall thickness by its resting end diastolic thickness and multiplying by 10 .

Diastolic function was assessed from the time constant of isovolumetric relaxation and regional left ventricular wall stiffness. The time constant of relaxation $(\mathrm{T} ; \mathrm{ms})$ was calculated as the negative reciprocal of the slope of the linear regression between pressure and negative $\mathrm{dP} / \mathrm{dt}$ during isovolumetric relaxation. ${ }^{18}$ The extrapolated baseline pressure $(\mathrm{Pb} ; \mathrm{mm} \mathrm{Hg})$ was calculated as the pressure at $\mathrm{dP} / \mathrm{dt}=0$. The isovolumetric relaxation period was defined as the time interval beginning immediately after maximum negative $\mathrm{dP} / \mathrm{dt}$ and ending when pressure had decreased to $5 \mathrm{~mm} \mathrm{Hg}$ above left ventricular end diastolic pressure. ${ }^{18}$

Regional passive elastic properties of the left ventricular wall were assessed from the diastolic pressure-wall thickness relationship between minimum left ventricular pressure and end diastole. An elastic model with shifting asymptote was used to calculate regional wall stiffness:

$$
\mathrm{P}=\mathrm{a} \times \mathrm{e}^{\mathrm{b} \times \mathrm{h}}+\mathrm{c}
$$

where $\mathrm{P}=\mathrm{left}$ ventricular pressure ( $\mathrm{mm} \mathrm{Hg}$ ), a=elastic constant $(\mathrm{mm} \mathrm{Hg}), \mathrm{b}=$ constant of regional wall stiffness $(1 / \mathrm{mm}), \mathrm{h}=$ normalised wall thickness $(\mathrm{mm})$, and $\mathrm{c}=$ asymptote of the exponential pressurewall thickness relationship ( $\mathrm{mm} \mathrm{Hg}$ ). The three constants, $\mathrm{a}, \mathrm{b}$ and $\mathrm{c}$, were determined by an iteration procedure designed by one of us ( $\mathrm{MJ}$ ). Operative regional left ventricular wall stiffness at a common preload of $10 \mathrm{~mm} \mathrm{Hg}$ was calculated as

\section{$\mathrm{dP} / \mathrm{dh}=\mathrm{b} \times(10-\mathrm{c})$}

where $\mathrm{dP} / \mathrm{dh}$ is the instantaneous wall stiffness at $10 \mathrm{~mm} \mathrm{Hg}$ $\left(\mathrm{mm} \mathrm{Hg} \cdot \mathrm{mm}^{-1}\right) .^{14}$ Left ventricular wall thickness at a common preload of $10 \mathrm{~mm} \mathrm{Hg}$ was calculated as

$$
\mathrm{h}=(\ln [10-\mathrm{c}]-\ln [\mathrm{a}]) / \mathrm{b}
$$

where $\ln$ is the natural logarithm.

\section{Statistics}

Statistical comparisons of haemodynamic data obtained during the control run, after $2 \mathrm{~min}$ and $2 \mathrm{~h}$ of ischaemia, after $4 \mathrm{~h}$ of reperfusion, and under dopamine were performed by an analysis of variance for repeated measurements. If the analysis was significant, the Scheffé procedure was applied. Comparisons of data between the control and nisoldipine group were carried out by the Mann-Whitney test for two independent groups. Values are given as means (SD).

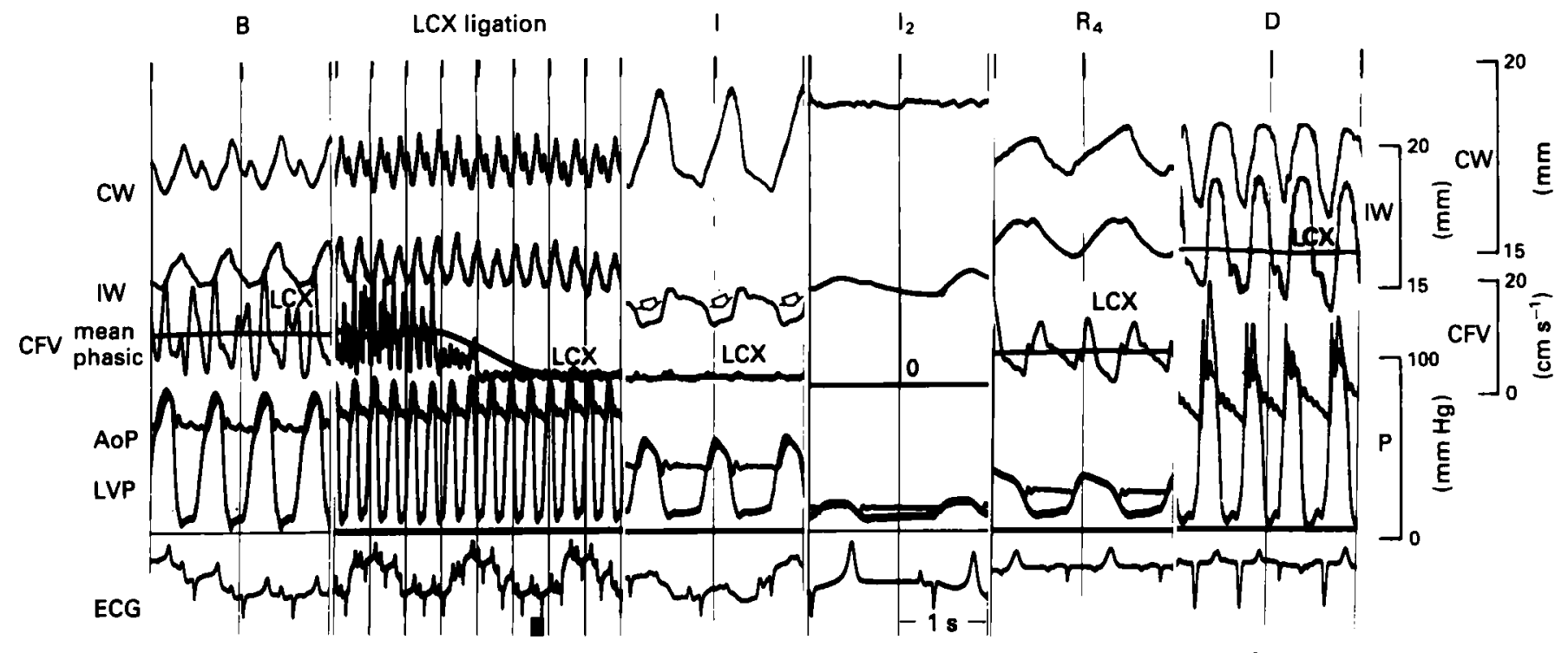

Figure 2 Original tracing showing the haemodynamic variables measured at rest $(B)$, during ligation of the left circumflex coronary artery $(L C X)$, after $2 \min (I)$ and $2 h\left(I_{2}\right)$ of ischaemia, after $4 h$ of reperfusion $\left(R_{4}\right)$, and during dopamine infusion $(D)$. Control $(C W)$ and ischaemic (IW) wall thickness, coronary flow velocity (CFV) of the $L C X$, left ventricular pressure (LVP) and aortic pressure (AoP) were measured in all animals. Systolic bulging of the ischaemic wall can be seen during acute ischaemia (arrows) but 4 h after reperfusion and during dopamine infusion ischaemic wall thickening is back to control. 


\section{Results}

Original tracings illustrating the variables measured are shown in figure 2 . One animal of each group developed ventricular fibrillation during ischaemia which could not be terminated despite several attempts. These two animals were therefore excluded from further evaluation. Severe hypotension (systolic pressure $<50 \mathrm{~mm} \mathrm{Hg}$ ) was observed during ischaemia and reperfusion in five of the 10 animals when the ventricular assist device was turned off.

Standard haemodynamic variables (table I)

Heart rate was slightly but not significantly lower in the animals treated with nisoldipine compared to the control animals. Peak systolic pressure decreased significantly during ischaemia and reperfusion and was back to control during dopamine infusion in the nisoldipine group, whereas the changes in the control group were not significant. End diastolic pressure did not change during the experiment and did not differ between the two groups. The time constant of relaxation increased in both groups during ischaemia and reperfusion and returned to control values during dopamine infusion. Nisoldipine tended to prolong relaxation, and this was significantly longer after 2 min of ischaemia than in the control group. The pressure baseline of the isovolumetric pressure decline at $\mathrm{dP} / \mathrm{dt}=0$ was slightly but not significantly higher in the nisoldipine group.

Coronary flow velocity (fig 3) and regional systolic function (table II)

Coronary flow velocity decreased significantly in the circumflex artery after ligation; however, flow was not zero. Coronary flow velocity in both the left anterior descending and the left circumflex coronary arteries was slightly although not significantly higher in the nisoldipine group (fig 3).

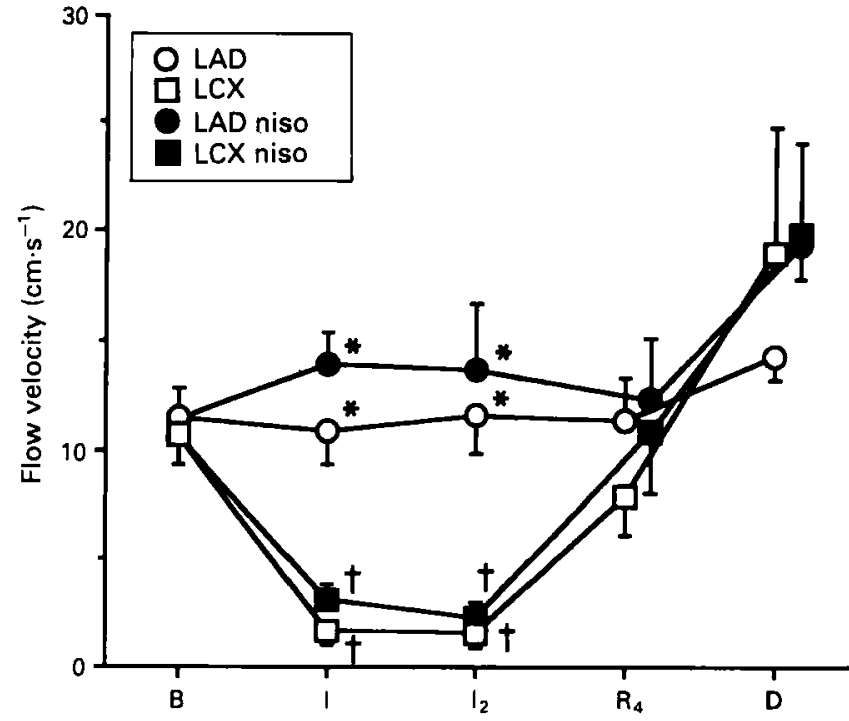

Figure 3 Coronary flow velocity of the left circumflex coronary artery ( $L C X=$ ischaemic wall region) and of the left anterior descending coronary artery ( $L A D=$ control wall region) at baseline $(B)$, after $2 \mathrm{~min}(I)$ and $2 h\left(I_{2}\right)$ of ischaemia, after $4 \mathrm{~h}$ of reperfusion $\left(R_{4}\right)$, and during dopamine infusion $(D)$. Values are means, bars $=S E M$. Coronary flow velocity remained unchanged in the $L A D$ but decreased significantly in the $L C X$ region after coronary ligation. Flow returned to control levels during reperfusion and increased significantly during dopamine infusion. Nisoldipine (niso) tended to increase coronary flow velocity compared to control (NS).

${ }^{*} p<0.05 \vee L C X ; \dagger p<0.05 \vee B$.

Left ventricular end diastolic wall thickness of the control wall remained unchanged in both groups during ischaemia and reperfusion; however, it was significantly greater in the nisoldipine group during dopamine infusion than in controls.

Table I Haemodynamic variables. Values are means $(S D), n=5$ per group

\begin{tabular}{|c|c|c|c|c|c|c|c|c|c|c|}
\hline & \multicolumn{2}{|c|}{ Heart rate (beats $\left.\mathrm{min}^{-1}\right)$} & \multicolumn{2}{|c|}{ LVEDP $(\mathrm{mm} \mathrm{Hg})$} & \multicolumn{2}{|c|}{$\operatorname{LVSP}(\mathrm{mm} \mathrm{Hg})$} & \multicolumn{2}{|l|}{$T(m s)$} & \multicolumn{2}{|c|}{$\mathrm{Pb}(\mathrm{mm} \mathrm{Hg})$} \\
\hline & $C$ & $N$ & $C$ & $N$ & C & $N$ & C & $N$ & C & $N$ \\
\hline Baseline & $116(9)$ & $102(22)$ & $11(6)$ & $11(4)$ & $90(21)$ & $89(6)$ & $46(7)$ & $50(9)$ & $-4(9)$ & $-1(7)$ \\
\hline Ischaemia (2 $\mathrm{min})$ & $117(10)$ & $94(23)$ & $13(6)$ & $15(4)$ & $83(18)$ & $64(17)$ & $47(12)$ & $78(28) \S$ & $-7(12)$ & $7(12)$ \\
\hline Ischaemia (2 h) & $106(10)$ & $80(22) \S$ & $11(4)$ & $12(4)$ & $62(13)$ & $47(21)^{*}$ & $73(26)$ & $88(34)$ & $-9(11)$ & $6(7)$ \\
\hline Reperfusion (4 h) & $101(33)$ & $78(28)$ & $16(7)$ & $13(7)$ & $69(19)$ & $55(19)^{*}$ & $73(42)$ & $91(26)^{*}$ & $-4(10)$ & $2(15)$ \\
\hline Dopamine infusion & $106(12)$ & $99(42)$ & $15(7)$ & $13(7)$ & $112(22) \dagger \ddagger$ & $87(30) \dagger \ddagger$ & $45(10)$ & $58(20)$ & $-6(12)$ & $-3(18)$ \\
\hline
\end{tabular}

$\mathrm{C}=$ control group; $\mathrm{N}=$ nisoldipine group; LVEDP=left ventricular end diastolic pressure; LSVP=left ventricular systolic pressure; $\mathrm{T}=\mathrm{time}$ constant of lef ventricular relaxation; $\mathrm{Pb}=$ pressure asymptote at $\mathrm{dP} / \mathrm{dt}=0$; ${ }^{*} \mathrm{p}<0.05 v$ baseline.

$\dagger \mathrm{p}<0.05 v$ ischaemia $(2 \mathrm{~h}) ; \ddagger \mathrm{p}<0.05 v$ reperfusion ( $4 \mathrm{~h}$ ) (ANOVA for repeated measures); $\$ \mathrm{p}<0.05 v$ control (Mann-Whitney test for independent groups)

Table II Left ventricular wall thickness and wall thickening. Values are means (SD), $n=5$ per group

\begin{tabular}{|c|c|c|c|c|c|c|c|c|}
\hline & \multicolumn{2}{|c|}{ CWed $(\mathrm{mm})$} & \multicolumn{2}{|c|}{ IWed $(\mathrm{mm})$} & \multicolumn{2}{|l|}{$\% C W$} & \multicolumn{2}{|l|}{$\% / W$} \\
\hline & $C$ & $N$ & $C$ & $N$ & $C$ & $N$ & C & $N$ \\
\hline Baseline & $10.0(0.0)$ & $10.0(0.0)$ & $10.0(0.0)$ & $10.0(0.0)$ & $9(4)$ & $10(5)$ & $9(2)$ & $10(7)$ \\
\hline Ischaemia (2 min) & $9.5(0.2)$ & $9.6(0.5)$ & $9.4(0.3)$ & $8.7(0.7)$ & $16(10)$ & $20(12)^{*}$ & $-6(5)^{*} \ddagger$ & $-7(10)^{*} \ddagger$ \\
\hline Ischaemia (2 h) & $10.2(1.3)$ & $10.3(0.4)$ & $9.1(0.9)$ & $9.6(0.8)$ & $4(6) \dagger$ & $5(9) \dagger$ & $-7(3)^{*} \ddagger$ & $-6(4)^{*} \ddagger$ \\
\hline Reperfusion (4 h) & $10.0(1.1)$ & $11.2(1.6)$ & $9.4(0.8)$ & $10.2(1.9)$ & $5(10) \dagger$ & $9(12) \dagger$ & $-2(3)^{*}$ & $-2(8)$ \\
\hline Dopamine infusion & $9.8(0.9)$ & $11.9(1.7) \dagger \S$ & $9.4(0.9)$ & $10.3(2.7)$ & $11(11)$ & $11(8)$ & $1(6) \ddagger$ & $6(8)$ \\
\hline
\end{tabular}

CWed, IWed=end diastolic wall thickness of the control and ischaemic wall, respectively; \%CW, \%IW=percent wall thickening of the control and ischaemic wall, respectively; other abbreviations as in table I. ${ }^{*} \mathrm{p}<0.05 v$ baseline.

$\nmid \mathrm{p}<0.05 v$ ischaemia ( $2 \mathrm{~min}$ ); (ANOVA for repeated measures); $\ddagger \mathrm{p}<0.05 v$ equivalent $\% \mathrm{CW}$ value; $\$ \mathrm{p}<0.05 v$ control (Mann-Whitney test for independent groups). 
No difference between the control and nisoldipine groups was found for end diastolic wall thickness of the ischaemic wall.

Systolic thickening of the control wall increased in both groups during $2 \mathrm{~min}$ of ischaemia, whereas the ischaemic wall showed systolic bulging with and without nisoldipine (table II). During dopamine infusion systolic thickening of the control wall was back to control values but thickening of the ischaemic wall showed persisting dysfunction which was slightly less after nisoldipine treatment.

\section{Regional diastolic function}

Regional wall stiffness at a common preload of $10 \mathrm{~mm} \mathrm{Hg}$ showed considerable differences between the control and the nisoldipine group (fig 4). Regional wall stiffness of the control wall was not altered throughout the experiment in either group. The ischaemic wall of the control group showed increased stiffness during ischaemia which did not return to control after reperfusion, whereas regional stiffness of the ischaemic wall remained unchanged during ischaemia and reperfusion in the nisoldipine group (fig 4). The reference wall thickness at a common preload of $10 \mathrm{~mm} \mathrm{Hg}$ did not change in the control wall region. In the ischaemic wall region of the control group, however, reference wall thickness decreased during ischaemia and reperfusion and was significantly thinner in the control than in the nisoldipine group (fig 5).

\section{Discussion}

Ventricular unloading by mechanical circulatory support is effective in protecting myocardial systolic function during long term myocardial ischaemia. ${ }^{10}{ }^{12}$ Mechanical unloading has been shown not only to prevent severe left ventricular dysfunction but also to salvage ischaemic myocardium when compared to reperfusion alone." The purpose of the present

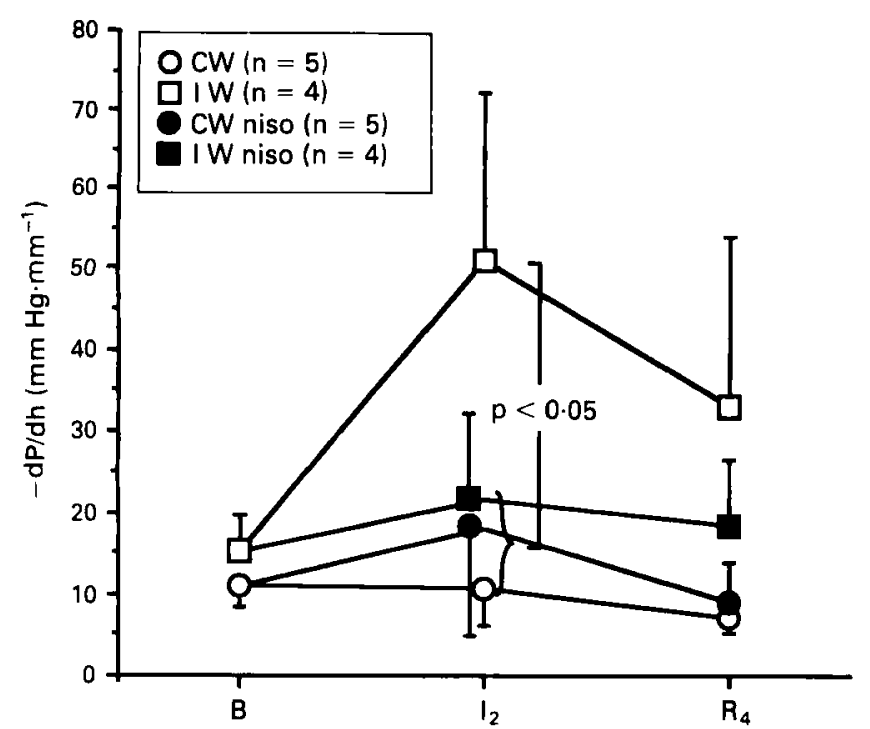

Figure 4 Regional wall stiffness $(-d P / d h)$ at a common preload of $10 \mathrm{~mm} \mathrm{Hg}$ of the control (CW; circles) and the ischaemic wall (IW; squares) at rest $(B)$, after $2 h$ of ischaemia $\left(I_{2}\right)$, and after 4 $h$ of reperfusion $\left(R_{4}\right)$ in the control (white symbols) and nisoldipine group (niso; black symbols). Values are means, bars=SEM. Regional stiffness of the ischaemic wall increased during ischaemia in the control group, whereas it remained unchanged in the nisoldipine group. Regional wall stiffness of the control wall remained unchanged throughout the experiment. study was to evaluate the influence of mechanical unloading on diastolic dysfunction and to study the effect of nisoldipine on regional passive elastic properties of the ischaemic and postischaemic myocardium.

\section{Regional coronary blood flow during ischaemia}

Long term myocardial ischaemia was associated with a significant reduction in coronary blood flow (fig 3) although flow was not zero after ligation of the left circumflex coronary artery. This might be explained by the presence of collateral perfusion or by some connections between the ligature and the flow probe. This collateral perfusion is certainly small but can be enhanced during ventricular unloading. " Thus collateral perfusion could explain some beneficial effect on the ischaemic myocardium. ${ }^{20}$ However, collateral perfusion is usually not enough to maintain normal left ventricular function during coronary ligation and hence systolic bulging occurred in all animals after ligation of the circumflex coronary artery (table II). Collateral flow was antegrade in the ligated circumflex artery, suggesting significant collaterals close to the coronary flow probe.

Regional left ventricular function during ischaemia

The ischaemic wall showed systolic bulging after occlusion of the circumflex artery, whereas hypercontractions occurred in the normal wall during the initial phase of ischaemia. This contrasting behaviour of the ischaemic and the normal wall is responsible for the occurrence of left ventricular asynchrony and the prolongation of relaxation. ${ }^{3} 2122$ Parallel with systolic dysfunction, there were changes in the passive elastic properties of the ischaemic wall, with increased regional stiffness. This has been reported previously..$^{3} 1923$ The increase in regional stiffness is probably due to several mechanisms such as systolic overstretch of the ischaemic myocardium, ${ }^{3}$ delayed relaxation with prolonged tension

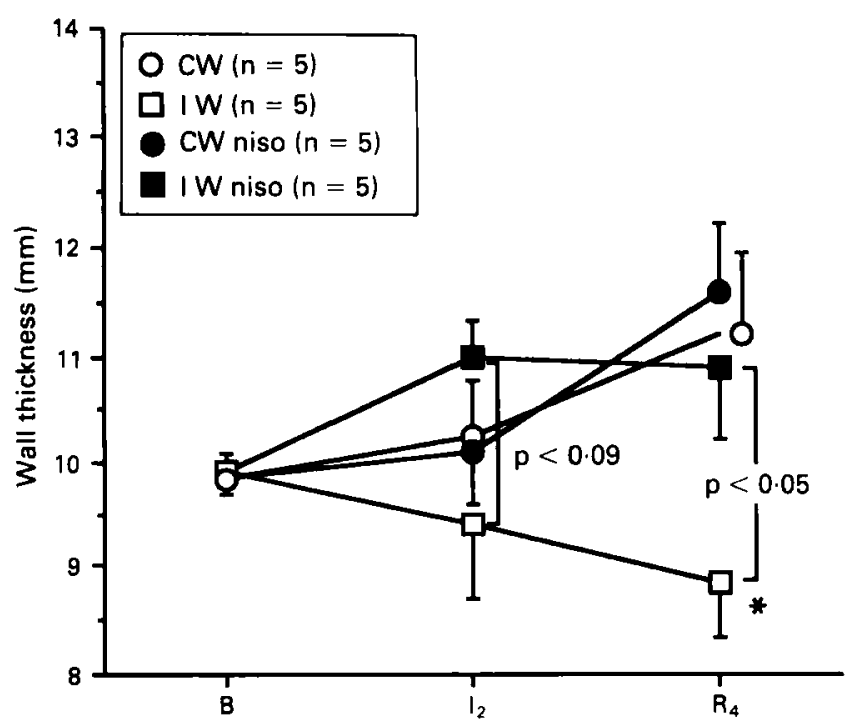

Figure 5 Control (CW; circles) and ischaemic (IW; squares) wall thickness at a common preload of $10 \mathrm{~mm} \mathrm{Hg}$ at rest $(B)$, after $2 h$ of ischaemia $\left(I_{2}\right)$, and after $4 h$ of reperfusion $\left(R_{4}\right)$ in the control (white symbols) and the nisoldipine group (niso; black symbols). Values are means, bars=SEM. Ischaemic wall thickness in the control group decreased during ischaemia and reperfusion when compared to the control wall but remained unchanged after nisoldipine treatment.

${ }^{*} p<0.05 \vee B$. 
decay during diastolic filling, ${ }^{3} 1924$ and/or diastolic calcium overload caused by impaired calcium sequestration of the sarcoplasmic reticulum. ${ }^{19} 2526$

\section{Regional left ventricular function of the postischaemic myocardium}

Postischaemic left ventricular function was characterised by persisting systolic bulging of the ischaemic wall four hours after reperfusion (table II), whereas function of the control wall returned to the baseline level at the end of reperfusion. Some recovery of regional left ventricular systolic function of the ischaemic wall was possible during dopamine infusion, suggesting that myocardial stunning had occurred. ${ }^{1}{ }^{27}$ However, systolic function of the postischaemic myocardium was not normalised during inotropic stimulation, indicating that there was some irreversible damage to the myocardium.

Diastolic dysfunction was characterised by prolongation of relaxation and increased regional wall stiffness. Asynergy prolongs the time constant of left ventricular relaxation. However, regional relaxation rates cannot be measured accurately with the currently available techniques in the intact heart. Thus the time constant of relaxation is a global parameter which is also dependent on loading conditions. ${ }^{28}$ With inotropic stimulation relaxation became normal, suggesting either an augmentation of global relaxation rates such as is shown to occur with the use of catecholamines, ${ }^{29} 30$ or the occurrence of reversible asynchrony of the left ventricle, probably due to the recovery of function of the ischaemic wall. Inotropic stimulation may augment relaxation by reducing asynchrony despite persistent ischaemia. ${ }^{31}$ In the control group, regional wall stiffness of the ischaemic myocardium was increased during ischaemia and reperfusion (fig 4). Thus regional differences in passive elastic properties occur during acute myocardial ischaemia of the left ventricle despite ventricular unloading by the assist device.

\section{Effect of nisoldipine on left ventricular function}

The effect of calcium antagonists on the ischaemic and postischaemic myocardium has been extensively studied in the past. ${ }^{32-34}$ An improvement in systolic dysfunction has been reported after pretreatment with nifedipine, ${ }^{35}$ verapamil, ${ }^{33}$ and other calcium channel blockers. ${ }^{36-38}$ In the present study little improvement in systolic function of the postischaemic myocardium was found after the administration of nisoldipine. However, regional diastolic wall stiffness at a common preload of $10 \mathrm{~mm} \mathrm{Hg}$ was less during ischaemia and reperfusion (fig 4), and diastolic thinning of the ischaemic wall was prevented by nisoldipine, suggesting that this calcium antagonist has a protective effect on the passive elastic properties of the ischaemic myocardium. This effect cannot solely be explained by a blockade of the slow calcium channels, ${ }^{34}$ and there are probably several mechanisms involved:

- Calcium antagonists delay the depletion of high energy phosphates during ischaemia by reducing myocardial contractility and protecting mitochondrial oxidative phosphorylation. ${ }^{39}$

- Pretreatment with verapamil has been shown to preserve sarcolemmal sodium-potassium-ATPase activity and to augment the removal of intracellular sodium which accumulates during ischaemia."

- Calcium antagonists reduce the influx of sodium by direct blockade of the sodium channel and thus attenuate sodium overload of the ischaemic myocyte. ${ }^{41}$
- Coronary collateral perfusion can be improved by calcium antagonists and thus reduce the extent of ischaemia. ${ }^{32}$

- Blockade of the slow calcium channels reduces intracellular calcium concentration during prolonged ischaemic states and thus reduces diastolic calcium overload of the postischaemic cell. ${ }^{35}$

\section{Clinical implications}

There are numerous clinical situations in which the myocardium is subjected to transient ischaemia, including unstable angina, acute myocardial infarction with reperfusion, open heart surgery with cardioplegic arrest, or cardiac transplantation. Recent observations suggest that these situations may be associated with myocardial stunning after short term ischaemia. In patients with long term ischaemia the myocardium might be variably damaged or may remain reversibly depressed for prolonged periods of time or even chronically (hibernating myocardium). The evidence found in the present study indicates that diastolic dysfunction can be effectively attenuated by pharmacological manipulations such as calcium antagonists. Several pathogenic mechanisms, for example preservation of high energy phosphates, preserved sarcolemmal sodiumpotassium-ATPase, and attenuation of sodium and/or calcium overload, might be interfering with the mechanism of cell injury. Thus calcium antagonists might prevent rather than simply temporarily correct postischaemic diastolic dysfuntion.

\section{Limitations of the study}

Mechanical circulatory support was performed in the present study to prevent postischaemic hypotension (systolic pressure $<50 \mathrm{~mm} \mathrm{Hg}$ ) which occurred in five of 10 animals. Without circulatory support half the animals would have been lost due to left ventricular dysfunction caused by the large ischaemic zone. On the other side, mechanical circulatory support certainly reduced the ischaemic damage by unloading the myocardium at risk and improving collateral perfusion. ${ }^{11}$

Coronary collateral perfusion was not directly measured except antegrade flow in the proximal circumflex artery. This flow does not necessarily reflect the total amount of collateral perfusion to the ischaemic myocardium.

Submitted 18 May 1992; accepted 9 September 1992. Time for review process 22 days.

Key terms: regional left ventricular function; pressure-wall thickness relationship; diastolic dysfunction; calcium antagonist: myocardial ischaemia; myocardial reperfusion.

1 Heyndrickx GR, Millard RW, McRitchie RJ, Maroko PR, Vatner SF. Regional myocardial function and electrophysiological alterations after brief coronary artery occlusion in conscious dogs. $J$ Clin Invest 1975;56:978-85.

2 Edwards $\mathrm{CH}$, Rankin JS, McHale PA, Ling D, Anderson R. Effects of ischemia on left ventricular regional function in the conscious dog. Am J Physiol 1981;240:H413-20.

3 Hess OM, Osakada G, Lavelle JF, Gallagher KP, Kemper WS, Ross J. Diastolic myocardial wall stiffness and relaxation during partial and complete coronary occlusions in the conscious dog Circ Res 1983:52:387-400.

4 Charlat ML, O'Neill PG, Hartley CJ, Roberts R, Bolli R. Prolonged abnormalities of left ventricular diastolic wall thinning in the "stunned" myocardium in conscious dogs: time course and relation to systolic function. J Am Coll Cardiol 1989:13:185-94.

5 Przyklenk K. Patel B, Kloner R. Diastolic abnormalities of postischemic "stunned" myocardium. Am J Cardiol 1987; 60: $1211-3$. 
6 Bolli R. Mechanism of myocardial stunning. Circulation 1990;82:723-38.

7 Anstadt MP, Malone JP, Brown JR, Nolan DS, Quinones JD, Anstadt GL. Direct mechanical ventricular assistance promotes salvage of ischemic myocardium. Trans Am Soc Artif Intern Organs 1987:33:720-5.

8 Magovern GJJ, Christlieb IY, Kao RL, et al. Recovery of the failing canine heart with biventricular support in a previously fatal experimental model. J Thorac Cardiovasc Surg 1987;94:656-63.

9 Wei C, Yada I, Kusagawa M. The effect of left ventricular assistance on the area of infarcted myocardium. Trans Am Soc Artif Intern Organs 1986;32:217-20.

10 Merhige M, Smalling R, Cassidy D, et al. Effect of the Hemopump left ventricular assist device on regional myocardial perfusion and function. Circulation 1989;80(suppl III):III-58-66.

11 Smalling RW, Cassidy DB, Barrett R, Lachterman B, Felli P, Amirian J. Improved regional blood flow, left ventricular unloading, and infarct salvage using an axial-flow, transvalvular left ventricular assist device. Circulation 1992;85:1152-9.

12 Tjon-A-Meeuw L, Hess OM, von Segesser LK, Suetsch G, Leskosek B, Turina M. Preservation of myocardial function by mechanical circulatory support during prolonged ischemia. Eur Heart J 1992;13:1549-55.

13 Ninet J, Jarolin G, Vigneron M, et al. Technique d'implantation des procédés d'assitance biventriculaire externe. Presse Med 1989;18:1024-7.

14 Wooley SR, Wesenhagen $H$, Jambroes G, Hitchcock JF Experience with the Abiomed biventricular support system. (Abstract) Eur Heart $J$ 1989;10:91.

15 von Segesser LK, Leskosek B, Rheda F, et al. Performance characteristics of a disposable ventricle assist device. Thorac Cardiovasc Surg 1988;36: 146-50.

16 Rankin JS, McHale PA, Arentzen CE, Ling D, Greenfield JC, Anderson RW. The three-dimensional dynamic geometry of the left ventricle in the conscious dog. Circ Res 1976;39:304-13.

17 Osakada G, Kumada T, Gallagher K, Kemper W, Ross J. Reduction of exercise-induced ischemic regional myocardial dysfunction by verapamil in conscious dogs. Am Heart $J$ 1981;101:707-12.

18 Carroll JD, Hess OM, Hirzel HO, Krayenbuehl HP. Exerciseinduced ischemia: the influence of altered relaxation on early diastolic pressures. Circulation 1983;67:521-8.

19 Bourdillon PD, Lorell BH, Mirsky I, Paulus WJ, Wynne J, Grossman W. Increased regional myocardial stiffness of the left ventricle during pacing-induced angina in man. Circulation 1983;67:316-23.

20 Sasayama S, Fujita M. Recent insights into coronary collateral circulation. Circulation 1992;85:1197-204.

21 Thompson DS, Waldron CB, Juul SM, et al. Analysis of left ventricular pressure during isovolumic relaxation in coronary artery disease. Circulation 1982;65:690-7.

22 Mirsky I, Pasipoularides A. Clinical assessment of diastolic function. Prog Cardiovasc Dis 1990;32:291-318.

23 Sasayama $S$, Nonogi H, Miyazaki. Changes of diastolic properties of the regional myocardium during pacing induced ischemia in human subjects. J Am Coll Cardiol 1985;5:599-606.

24 Brutsaert DL, Rademakers FE, Sys SU. Triple control of relaxation: implications in cardiac disease. Circulation 1984, 69: $190-6$.

25 Morgan JP. Abnormal intracellular modulation of calcium as a major cause of cardiac contractile function. $N$ Engl $J$ Med $1991 ; 325: 625-32$.

26 Grossman W. Diastolic dysfunction in congestive heart failure. $N$ Engl J Med 1991;325: 1557-64.

27 Kloner RA, Przyklenk K, Patel B. Altered myocardial states. Am J Med 1989:86:14-22.

28 Zile M, Gaasch W. Load dependent left ventricular relaxation in conscious dogs. Am J Physiol 1991;261:H-691-9.

29 Morad M, Rolett E. Relaxing effects of catecholamines on mammalian heart. I Physiol (Lond) 1972;224:537-58.

30 Carroll JD, Lang RM, Neumann AL, Borow KM, Rajfer SI. The differential effects of positive inotropic and vasodilator therapy on diastolic properties in patients with congestive cardiomyopathy. Circulation 1986;74:815-25.

31 Udelson J, Cannon R, Bacharach S, Rumble T, Bonow R. Betaadrenergic stimulation with isoproterenol enhances left ventricular diastolic performance in hypertrophic cardiomyopathy despite potentiation of myocardial ischemia. Circulation 1989; 79:371-82.

32 Henry PD, Shuchleib R, Borda LJ, Roberts R, Williamson JR, Sobel BE. Effects of nifedipine on myocardial perfusion and ischemic injury in dogs. Circ Res 1978;43 372-80.

33 Bourdillon PD, Poole-Wilson PA. The effects of verapamil, quiescence, and cardioplegia on calcium exchange and mechanical function in ischemic myocardial function in ischemic rabbit myocardium. Circ Res 1982;50:360-8.

34 Tani M. Mechanisms of calcium overload in reperfused ischemic myocardium. Annu Rev Physiol 1990;52:543-59.

35 Henry PD, Shuchleib R, Davis J, Weiss ES, Sobel BE. Myocardial contracture and accumulation of mitochondrial calcium in ischemic rabbit heart. Am J Physiol 1977;233:H677-84.

36 Henry PD, Wahl AM. Diltiazem and nitrendipine suppress hypoxic contracture in quiescent ventricular myocardium. Eur Heart $J$ 1983;4:819-22.

37 Opie LH. Reperfusion injury and its pharmacologic modification. Circulation 1989;80:1049-62.

38 Nayler WJ, Buckley DJ, Leong J. Calcium antagonists and the "stunned" myocardium. Cardioscience 1990;1:61-4.

39 Nayler WG, Ferrari R, Williams A. Protective effect of pretreatment with verapamil, nifedipine and propanolol on mitochondrial function in the ischemic and reperfused myocardium. Am J Cardiol 1980;46:242-8.

40 Daly MJ, Elz JS, Nayler WG. The effects of verapamil on ischemia-induced changes in the sarcolemma. $J \mathrm{Mol}$ Cell Cardiol 1985;17:667-74.

41 Yatani A, Kunze DL, Brown AM. Effects of dihydroperidine calcium channel modulators on cardiac sodium channels. Am J Physiol 1988;254:H140-7.

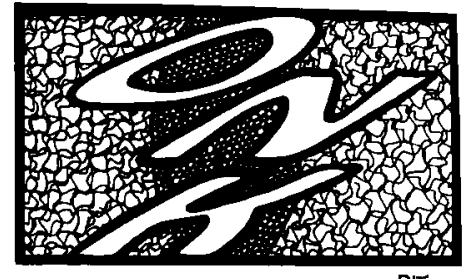

DI 